\title{
Mixed Species Allometric Models for Estimating above-Ground Liana Biomass in Tropical Primary and Secondary Forests, Ghana
}

\author{
Patrick Addo-Fordjour ${ }^{1,2}$ and Zakaria B. Rahmad ${ }^{1}$ \\ ${ }^{1}$ School of Biological Sciences, Universiti Sains Malaysia, 11800 Pulau Penang, Penang, Malaysia \\ ${ }^{2}$ Department of Theoretical and Applied Biology, College of Science, Kwame Nkrumah University of Science and \\ Technology (KNUST), Kumasi, Ghana
}

Correspondence should be addressed to Patrick Addo-Fordjour; paddykay77@yahoo.com

Received 18 June 2013; Accepted 13 August 2013

Academic Editors: W. de Vries, N. Frascaria-Lacoste, Z. Kaya, and T. L. Noland

Copyright (C) 2013 P. Addo-Fordjour and Z. B. Rahmad. This is an open access article distributed under the Creative Commons Attribution License, which permits unrestricted use, distribution, and reproduction in any medium, provided the original work is properly cited.

\begin{abstract}
The study developed allometric models for estimating liana stem and total above-ground (TAGB) biomass in primary and secondary forests in the Asenanyo Forest Reserve, Ghana. Liana biomass was determined for 50 individuals for each forest using destructive sampling. Various predictors involving liana diameter and length were run against liana biomass in regression analysis, and $R^{2}$, RMSE, and Furnival's index of fit (FI) were used for model comparison. The equations comprised models fitted to untransformed and log-transformed data. Forest type had a significant influence $(P<0.05)$ on liana allometric models in the current study, resulting in the development of forest-type-specific equations. There were significant and strong linear relationships between liana biomass and the predictors in both forests $\left(R^{2}>0.970\right)$. Liana diameter was a better predictor of biomass than liana length. Generally, the models which were based on log-transformed data showed better fit (higher FI values) than those fitted to untransformed data. Comparison of the site specific models in the current study with previously published models indicated that the models of the current study differed from the previous ones. This indicates the need for forest specific equations to be used for accurate determination of above-ground liana biomass.
\end{abstract}

\section{Introduction}

Lianas are important structural component of tropical forests [1]. They perform a number of ecological functions which help to sustain tropical forest ecosystems [2]. Lianas add substantially to plant assemblages in tropical forests in terms of number of species [3] and stem density [4]. Apart from contributing directly to species diversity in tropical forests, lianas also play a number of roles which contribute to maintain diversity of other organism [5]. Due to relatively high dominance of lianas in tropical forests, they also contribute a lot to forest biomass, especially in heavy liana infested forests. Specifically, lianas can accumulate as high as 30\% of total above-ground biomass in tropical forest ecosystems [2]. Comparatively, lianas devote much less biomass for stem support than tress, and therefore, they are able to allocate more biomass for their growth compared with trees $[2,5]$.
Consequently, lianas have higher biomass growth than trees [6]. Lianas allocate more biomass for leaf production than the amount of biomass allocated to their stems. Because lianas allocate less biomass to their stems they produce less dense wood compared to trees [7].

Estimating tropical forest biomass and determining its dynamics are important aspects of tropical forest ecology. These are more important in areas where changes in composition and structure of forests are apparent. Although changes in biomass levels in secondary forests may occur often due to persistent human disturbance, primary forest biomass may also undergo changes due to other factors which bring about changes in forest composition, structure, diversity, and productivity $[8,9]$. In view of this, it is necessary for biomass studies to be conducted in both tropical primary and secondary forests. However, at the moment, most biomass assessment studies have been limited to secondary forests, 
neglecting tropical primary forests. Available data on the amounts of biomass within a forest is not only important in determining the amounts of carbon stored by that forest [10] but also essential in assessing the productivity, structure, and conditions of that forest [11]. In addition, biomass data on secondary forests could be useful in explaining the effects of deforestation and carbon sequestration on the global carbon balance [10]. As indicated above, lianas already contribute substantially to total above-ground biomass in heavily lianainfested tropical forests (cf. [4]). As human disturbance continues to increase in tropical forests, especially in developing countries, lianas would most likely continue to increase in abundance, which could ultimately lead to an increase in the amount of biomass they store. In spite of the ability of lianas to store high amounts of biomass in tropical forest ecosystems, they have been ignored in most biomass assessment studies in the world [12]. It appears that many experts in the area are oblivious of the significant contribution lianas can make to forest biomass. This could explain why most recent calls about the need to increase the number of biomass and carbon stock assessments of tropical forests have all been centered on trees only [13].

The easiest and most practical way to determine liana biomass in tropical forests is to employ allometric equations. The use of allometric equations in estimating plant biomass does not only avoid forest destruction but also allows for the estimation of large forest areas. This is because data on the estimators of plant biomass in allometric models can easily be obtained for large areas of forests within a relatively short period of time without harvesting them. Nonetheless, allometric models can sometimes yield biomass estimates that do not reflect the biomass content of a forest [14]. Due to the apparent lack of knowledge about the importance of lianas in storing biomass, and their neglect in forest biomass assessments, only a few liana allometric equations have been developed for them. The limited number of liana allometric equations is also partly due to the difficulty in accessing the whole length of lianas from trees [15]. In spite of this challenge, conscious efforts should be made to develop many liana allometric equations that can be used to accurately estimate the increasing liana biomass in tropical forests [2]. This would ensure that biomass estimates of tropical forests are a true reflection of the actual biomass contents of forests. The availability of plant part allometric equations enable biomass allocation of plant parts to be determined and assessed. Knowledge of biomass allocation changes in different plant parts can be used to assess changes in plant structure and biogeochemical cycles in tropical forests (cf. [16]). In spite of this, only one study [17] has developed allometric equations for liana leaves and total above-ground part. The present study therefore sought out to develop allometric equations for different liana parts.

Ghana has some of the most complex and biodiversityrich tropical forests in which lianas feature prominently [21, 22]. Nevertheless, there is no allometric equation for lianas in Ghana and also in the whole of Africa. The current study developed allometric models for the estimation of aboveground biomass of lianas in primary and secondary forests within the Asenanyo Forest Reserve, Ghana. Allometric
TABLE 1: Number of individuals of liana species in the primary and secondary forests used for the allometric equations.

\begin{tabular}{|c|c|c|}
\hline \multirow{2}{*}{ Species } & \multicolumn{2}{|c|}{ Number of individuals } \\
\hline & Primary forest & Secondary forest \\
\hline Acacia pentagona & 3 & 3 \\
\hline Adenia rumicifolia & 2 & - \\
\hline Afrobrunnichia erecta & 2 & 1 \\
\hline Agelaea paradoxa & 2 & 2 \\
\hline Alafia barteri & 4 & 2 \\
\hline Alafia whytei & 3 & 3 \\
\hline Calycobolus africanus & 2 & 2 \\
\hline Calycobolus heudelotii & 2 & 2 \\
\hline Castanola paradoxa & - & 2 \\
\hline Combretum paradoxum & 2 & 2 \\
\hline Combretum sp. & 3 & 2 \\
\hline Dalbergia hostilis & 2 & 3 \\
\hline Dalbergiella welwitschii & 2 & 1 \\
\hline Gogronema latifolium & - & 2 \\
\hline Griffonia simplicifolia & 3 & 2 \\
\hline Landolphia hirsuta & 2 & 2 \\
\hline Leptoderris micrantha & 2 & 2 \\
\hline Manniophyton fulvum & - & 2 \\
\hline Millettia chrysophylla & 4 & 3 \\
\hline Motandra guineensis & 2 & 2 \\
\hline Neuropeltis sp. & 1 & 2 \\
\hline Parquetina nigrescens & 2 & - \\
\hline Paullinia pinnata & 2 & 2 \\
\hline Salacia elegans & 2 & 2 \\
\hline Salacia columna & - & 2 \\
\hline Strophanthus barteri & 1 & 2 \\
\hline
\end{tabular}

equations in the present study were developed for both stem and total above-ground components of lianas. Total aboveground biomass of lianas is usually made up of stem and leaf (shoot) biomass components. Therefore, development of stem and total above-ground biomass equations in the current study makes it possible to also estimate liana leaf biomass. This would enable changes in relative contribution of various liana parts to total above-ground biomass to be assessed from time to time. This information together with other similar ones from other plant life forms, such as trees, can be useful in assessing forest ecosystem dynamics which can help in developing forest management strategies.

\section{Materials and Methods}

2.1. Study Area. The study was conducted in the Asenanyo Forest Reserve in the Nkwawie District, Ghana $\left(06^{\circ} 26^{\prime} 23^{\prime \prime} \mathrm{N}\right.$, $02^{\circ} 06^{\prime} 28^{\prime \prime} \mathrm{W}$ ). The forest reserve lies within the moist semideciduous forest zone in Ghana and has both primary and secondary forests. The secondary forest has undergone selective and illegal logging as well as silvicultural treatments in the past, and the relics of these human activities are still evident. The dominant species in the forest are Celtis mildbraedii, Triplochiton scleroxylon, Albizia zygia, and Cedrella odorata. 
TABLE 2: Summary of allometric properties of liana individuals in the two forest types (Asenanyo Forest Reserve) used for the study.

\begin{tabular}{|c|c|c|c|c|c|c|}
\hline \multirow{2}{*}{ Parameter } & \multicolumn{3}{|c|}{ Primary } & \multicolumn{3}{|c|}{ Secondary } \\
\hline & Min. & Max. & Mean & Min. & Max. & Mean \\
\hline Diameter $(\mathrm{cm})$ & 1.20 & 13.20 & 6.34 & 1.20 & 13.00 & 5.78 \\
\hline Length (m) & 5.07 & 47.55 & 18.33 & 4.96 & 52.00 & 16.12 \\
\hline Stem biomass (kg) & 3.00 & 25.10 & 11.20 & 2.05 & 21.60 & 10.65 \\
\hline Total above-ground biomass (kg) & 3.55 & 27.15 & 12.04 & 2.21 & 24.80 & 11.63 \\
\hline
\end{tabular}

TABLE 3: Six previously published allometric equations (total aboveground liana biomass) used in comparing the current allometric equation. All the equations are based on the model form; total aboveground biomass $=\exp [c+\alpha \ln ($ Diameter $)]$.

\begin{tabular}{lcc}
\hline Equation & $c$ & $\alpha$ \\
\hline Gehring et al. (2004) [17] & -1.547 & 2.640 \\
Gerwing and Farias (2000) [12] & 0.147 & 2.184 \\
Putz (1983) [18] & 0.036 & 1.806 \\
Hozumi et al. (1969) [19] & -1.347 & 2.391 \\
Beekman (1981) [20] & -1.459 & 2.566 \\
Schnitzer et al. (2006) [4] & -1.484 & 2.657 \\
\hline
\end{tabular}

The average elevation of the forest reserve is $162 \mathrm{~m}$ a.s.l. Daily temperatures range from 20 to $32.9^{\circ} \mathrm{C}$, and the average annual rainfall is $1856 \mathrm{~mm}$. Relative humidity for the area is high (91\%).

2.2. Field Sampling and Biomass Measurements. A total of 22 and 24 liana species were destructively sampled from the primary and secondary forest, respectively (Table 1), for development of mixed species allometric equations (from August to December 2012). Sampling was purposely conducted in the rainy season when leaf biomass was highest [17]. Lianas were harvested from different habitats (flatlands, slopes, and undulating lands) which were comparable in the primary and secondary forests. Because in each forest type sampling occurred in flatlands, slopes, and undulating lands which were comparable with those in the other forest type, habitat biased sampling was avoided. The sampling within different habitats in each forest type was to ensure that the models produced could be a reflection of habitat variations in the forests. Liana diameter (at $1.3 \mathrm{~m}$ from the rooting base) was measured before harvesting the individuals, whereas their length was measured after they were harvested. A total number of 100 liana individuals (primary forest: 50 individuals; secondary forest: 50 individuals) were harvested in the study (Table 1), and their allometric characteristics are indicated in Table 2. Both single and multiple stem liana individuals were included in the study. Liana leaves and stems were separated from each other, and they were sun dried to constant weights over different periods of time (leaves: 3 weeks; stems: 3 months). The constant dry weights of the species were recorded as their biomass.

2.3. Data Analyses. Data analyses involved data exploration and model fitting using liana diameter, $[\text { diameter }]^{2}$, length, $\log _{10}$ [diameter], and $\log _{10}[\text { diameter }]^{2}$ as estimators of liana biomass to obtain models that best fit the data. A series of models were developed using original untransformed and $\log$-transformed $\left(\log _{10}\right)$ data. In all cases, only models that complied with regression assumptions (homogeneity of variance, linearity, normality, and nonautocorrelation) and showed high goodness of fit $\left(R^{2}>0.97\right)$ were retained. Homogeneity of variance and linearity of data were assessed using residual plots while autocorrelation, and normality were verified with Durbin-Watson statistics and probability plots, respectively. The Furnival's index (FI), root mean square error (RMSE), and coefficient of determination (adjusted $R^{2}$ ) were used for model selection and comparison. The FI was used to compare models that had different response variables while the RMSE and $R^{2}$ were used for models with the same response variables. The RMSE and $R^{2}$ could not be used to compare models with different response variables because they have the potential of producing misleading results for that purpose $[23,24]$. For this reason, the Furnival's index [25] was used to compare untransformed and log-transformed models. The index was computed as follows:

$$
\mathrm{FI}=\frac{1}{\left[f^{\prime}(Y)\right]} \sqrt{\mathrm{MSE}}
$$

where $f^{\prime}(Y)$ is the derivative of the dependant variable with respect to biomass, MSE is the mean square error of the fitted equation, and the square bracket $([\cdot])$ is the geometric mean. Comparatively, models with lower FI and RMSE values have better goodness of fit. On the other hand, the higher the $R^{2}$ value of a model the better its goodness of fit.

Due to downward bias which usually occurs when log biomass are back transformed to arithmetic units [26], a correction factor (CF) indicated below [27] was calculated for the models, which could be used to correct them.

Consider

$$
\mathrm{CF}=\exp ^{\left((\mathrm{SEE} * 2.303)^{2} / 2\right)},
$$

where SEE is the standard error of the estimate.

Linear regression analyses were conducted to determine the relationships between liana biomass and the response variables (diameter, [diameter] ${ }^{2}$, length, $\log _{10}$ [diameter], or $\log _{10}[\text { diameter }]^{2}$ ) in the case of both untransformed and log-transformed data. Analysis of covariance (ANCOVA) was conducted to examine possible differences in regression slopes of models between the forest types. Forest type (primary and secondary) was used as the main factor, whereas the response variables (diameter, $[\text { diameter }]^{2}$, 
TABLE 4: Allometric equations of mixed species for estimating liana stem biomass $(\mathrm{kg})$ in the primary forest.

\begin{tabular}{lccccrr}
\hline$\#$ & Equation & $c( \pm$ SE $)$ & $\alpha( \pm$ SE $)$ & $R^{2}$ (adjusted) & RMSE & FI \\
\hline 1 & Stem biomass $=c+\alpha D$ & $1.643 \pm 0.128$ & $1.770 \pm 0.020$ & 0.994 & 0.471 & 0.47 \\
2 & Stem biomass $=c+\alpha L$ & $2.304 \pm 0.212$ & $0.294 \pm 0.006$ & 0.981 & 0.821 & 0.82 \\
3 & $\log _{10}($ Stem biomass $)=c+\alpha\left(\log _{10} D\right)$ & $1.004 \pm 0.013$ & $0.801 \pm 0.008$ & 0.996 & 0.036 & 0.35 \\
4 & $\log _{10}($ Stem biomass $)=c+\alpha\left(\log _{10} D^{2}\right)$ & $1.004 \pm 0.013$ & $0.958 \pm 0.009$ & 0.996 & 0.036 & 0.35 \\
\hline
\end{tabular}

\#: Equation number; $D$ : Liana diameter; $L$ : Liana length.

TABLE 5: Allometric equations of mixed species for estimating total above-ground biomass (TAGB) (kg) in the primary forest.

\begin{tabular}{|c|c|c|c|c|c|c|}
\hline$\#$ & Equation & $c( \pm \mathrm{SE})$ & $\alpha( \pm \mathrm{SE})$ & $R^{2}$ (adjusted) & RMSE & FI \\
\hline 5 & TAGB $=c+\alpha D$ & $1.703 \pm 0.131$ & $1.915 \pm 0.021$ & 0.994 & 0.484 & 0.48 \\
\hline 6 & $\mathrm{TAGB}=c+\alpha L$ & $2.425 \pm 0.234$ & $0.318 \pm 0.007$ & 0.980 & 0.903 & 0.90 \\
\hline 7 & $\log _{10}(\mathrm{TAGB})=c+\alpha\left(\log _{10} D\right)$ & $1.077 \pm 0.012$ & $0.850 \pm 0.007$ & 0.996 & 0.034 & 0.35 \\
\hline 8 & $\log _{10}(\mathrm{TAGB})=c+\alpha\left(\log _{10} D^{2}\right)$ & $1.077 \pm 0.012$ & $0.979 \pm 0.009$ & 0.996 & 0.034 & 0.35 \\
\hline
\end{tabular}

\#: Equation number; $D$ : Liana diameter; L: Liana length.

TABLE 6: Allometric equations of mixed species for estimating liana stem biomass $(\mathrm{kg})$ in the secondary forest.

\begin{tabular}{|c|c|c|c|c|c|c|}
\hline$\#$ & Equation & $c( \pm \mathrm{SE})$ & $\alpha( \pm \mathrm{SE})$ & $R^{2}$ (adjusted) & RMSE & FI \\
\hline 9 & Stem biomass $=c+\alpha D$ & $-0.341 \pm 0.119$ & $1.727 \pm 0.016$ & 0.996 & 0.414 & 0.41 \\
\hline 10 & Stem biomass $=c+\alpha L$ & $0.765 \pm 0.282$ & $0.446 \pm 0.011$ & 0.972 & 1.054 & 1.05 \\
\hline 11 & $\log _{10}($ Stem biomass $)=c+\alpha\left(\log _{10} D\right)$ & $0.201 \pm 0.009$ & $1.115 \pm 0.011$ & 0.994 & 0.022 & 0.20 \\
\hline 12 & $\log _{10}($ Stem biomass $)=c+\alpha\left(\log _{10} D^{2}\right)$ & $0.201 \pm 0.009$ & $0.498 \pm 0.006$ & 0.994 & 0.022 & 0.20 \\
\hline
\end{tabular}

\#: Equation number; $D$ : Liana diameter; $L$ : Liana length.

TABLE 7: Allometric equations of mixed species for estimating total above-ground biomass (TAGB) (kg) in the secondary forest.

\begin{tabular}{|c|c|c|c|c|c|c|}
\hline$\#$ & Equation & $c( \pm \mathrm{SE})$ & $\alpha( \pm \mathrm{SE})$ & $R^{2}$ (adjusted) & RMSE & FI \\
\hline 13 & TAGB $=c+\alpha D$ & $-0.360 \pm 0.124$ & $1.901 \pm 0.017$ & 0.996 & 0.433 & 0.43 \\
\hline 14 & $\mathrm{TAGB}=c+\alpha L$ & $0.774 \pm 0.294$ & $0.491 \pm 0.011$ & 0.975 & 1.100 & 1.10 \\
\hline 15 & $\log _{10}(\mathrm{TAGB})=c+\alpha\left(\log _{10} D\right)$ & $0.236 \pm 0.009$ & $1.128 \pm 0.012$ & 0.994 & 0.023 & 0.22 \\
\hline 16 & $\log _{10}($ TAGB $)=c+\alpha\left(\log _{10} D^{2}\right)$ & $0.236 \pm 0.009$ & $0.514 \pm 0.006$ & 0.994 & 0.023 & 0.22 \\
\hline
\end{tabular}

\#: Equation number; $D$ : Liana diameter; $L$ : Liana length.

length, $\log _{10}[$ diameter $]$, or $\log _{10}[\text { diameter }]^{2}$ ) were used as the covariables.

In the current study, the overall best total above-ground biomass models were determined for the forest types according to the Furnial's index of fit. These were compared with previous total above-ground liana biomass models indicated in Table $3[4,12,17-20]$, using paired $t$-tests. The equations were applied to data sets collected from the forests from which the current allometric equations were developed. The data are comprised of 92 (from 32 species) and 100 (from 32 species) liana individuals in the primary and secondary forests, respectively, (diameter range; primary forest: 2$10.7 \mathrm{~cm}$ and secondary forest: 2 to $14 \mathrm{~cm}$ ). Some of the data pairs were transformed (square root and log transformations) to meet $t$-test assumptions.

Regression analyses and $t$-test were performed using GenStat software (VSN International Ltd., Hemel Hempstead, UK) whereas ANCOVA was run with Minitab 15 Software (Minitab Inc.). All analyses were conducted at a significance level of $5 \%$.

\section{Results and Discussion}

Same set of allometric equations can be developed for use in both primary and secondary forests in areas where forest type does not influence the equations significantly [15, 17]. However, in this study, there were significant differences in the slopes of regression models between the primary and secondary forest types (ANCOVA; $P<0.05$ ). This suggested forest-specific differences in regressions between the primary and secondary forests, resulting in the development of forestspecific models for the primary and secondary forests.

In each forest, a total of four different models were developed for the estimation of liana stem and total aboveground biomass (Tables 4, 5, 6, and 7). These models were developed based on untransformed (models 1-2, 5-6, 9-10, and 13-14) and log-transformed (3-4, 7-8, 11-12, and 15-16) data. There were strong and significant linear relationships between liana biomass and the various predictors in all the models developed (Tables 4-7; Figures 1 and 2). Although liana diameter and length were good predictors of liana 


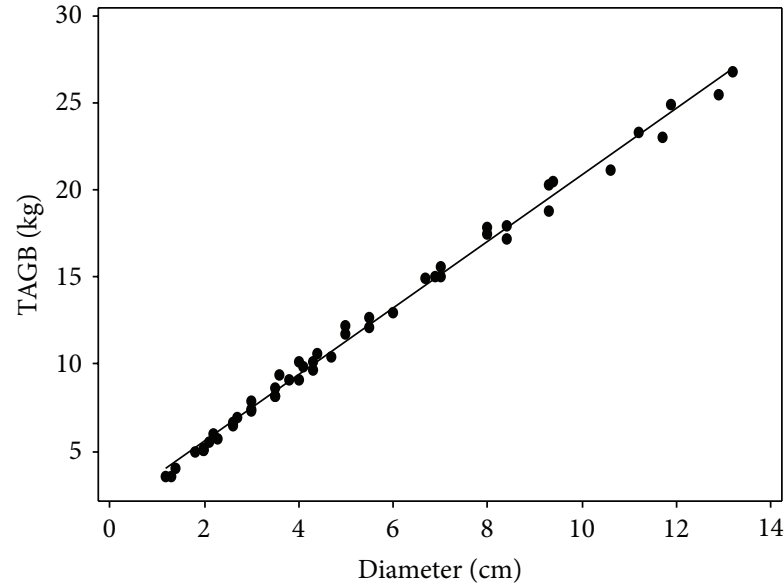

(a)

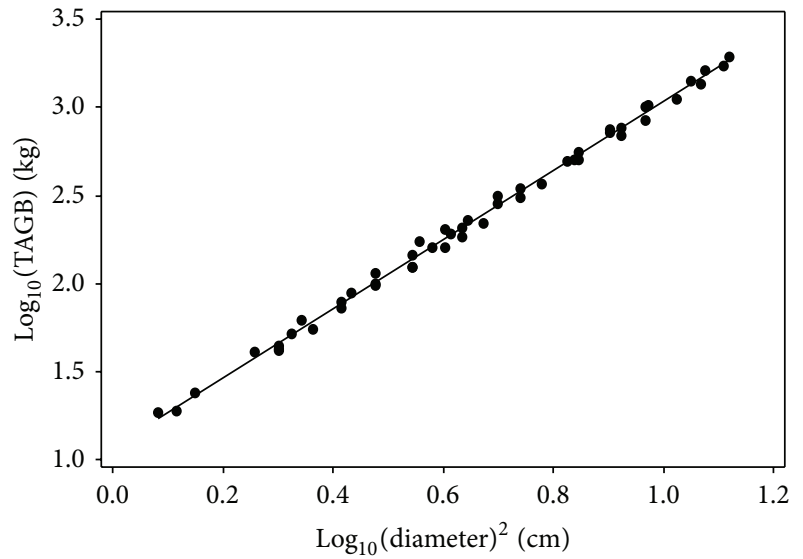

(c)

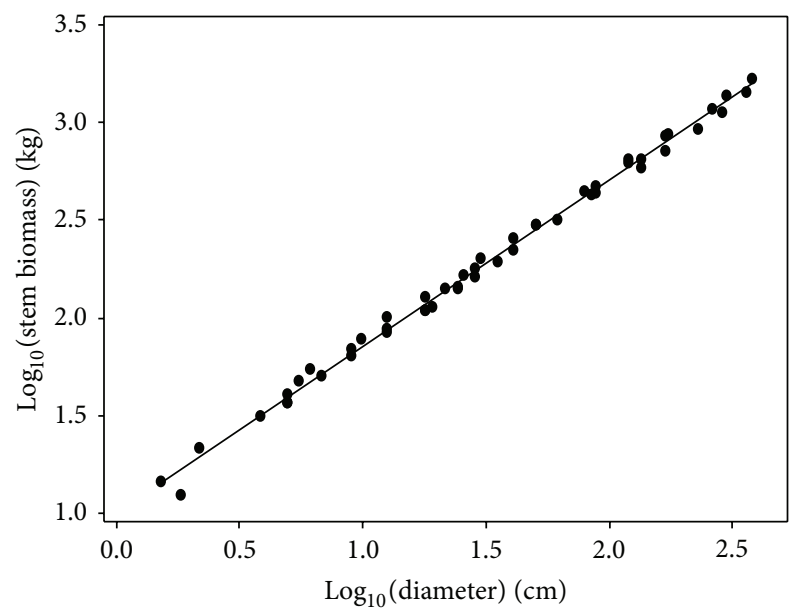

(e)

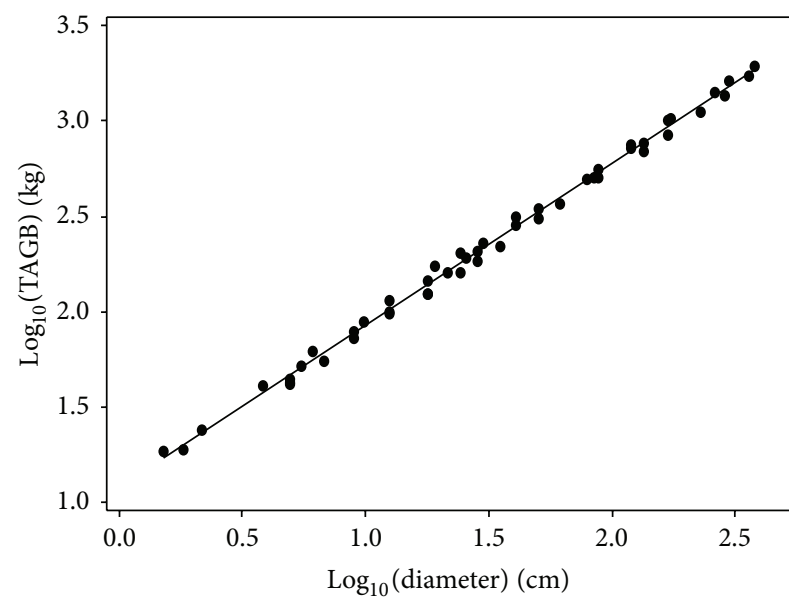

(b)

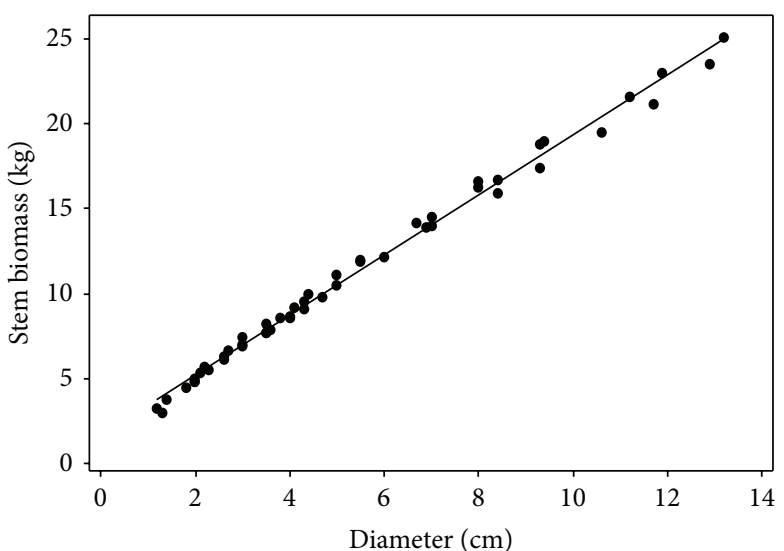

(d)

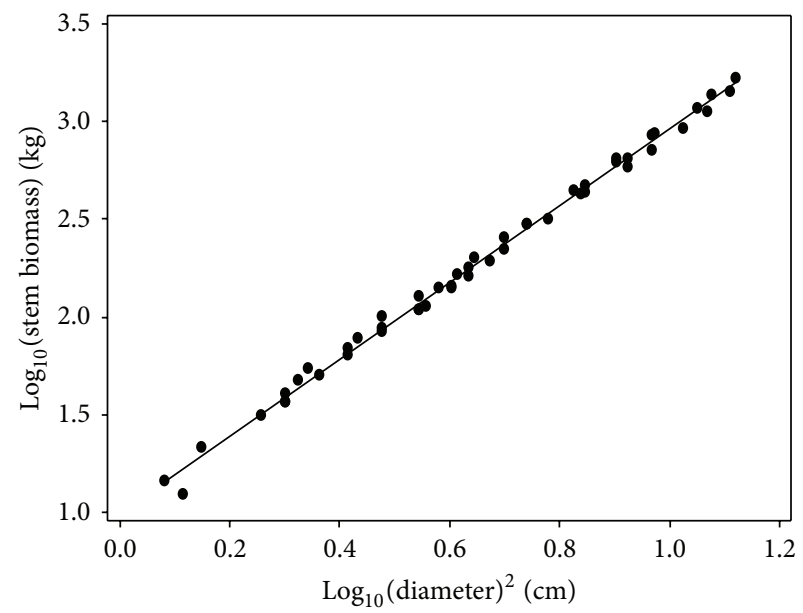

(f)

FIGURE 1: Allometric relationships between liana biomass (total above-ground biomass, TAGB: (a), (b), and (c); stem biomass: (d), (e), and (f)) and diameter in the primary forest. Relationships based on raw and log-transformed data are shown.

biomass in the models fitted to data on arithmetic scale, liana diameter $\left(R^{2}=0.994-0.996\right.$; RMSE $\left.=0.414-0.484\right)$ was slightly a better predictor of liana biomass than liana length $\left(R^{2}=0.972-0.981\right.$; RMSE $\left.=0.821-1.100\right)$ in the current study. The use of liana allometric equations that use length as a predictor of biomass has a practical challenge. Measuring liana length on the field is impossible unless they are harvested. Therefore, the allometric models of the current study which use liana diameter as a predictor of biomass are recommended for use in liana biomass determination. 


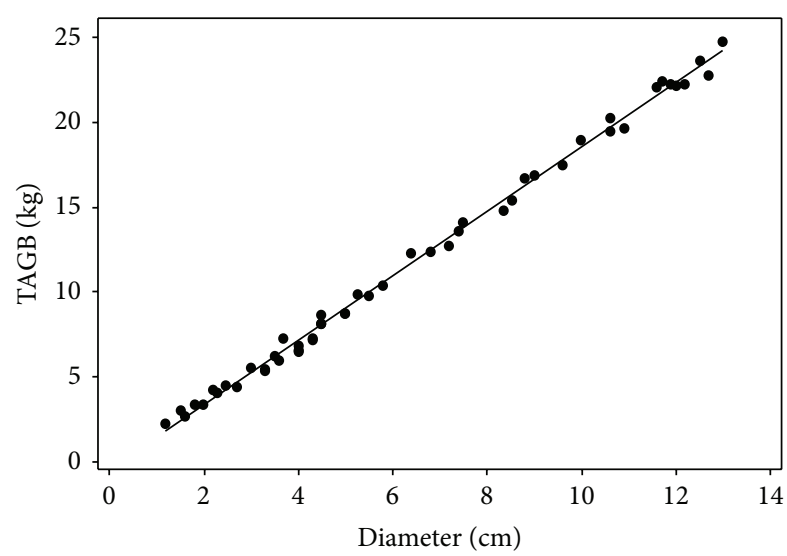

(a)

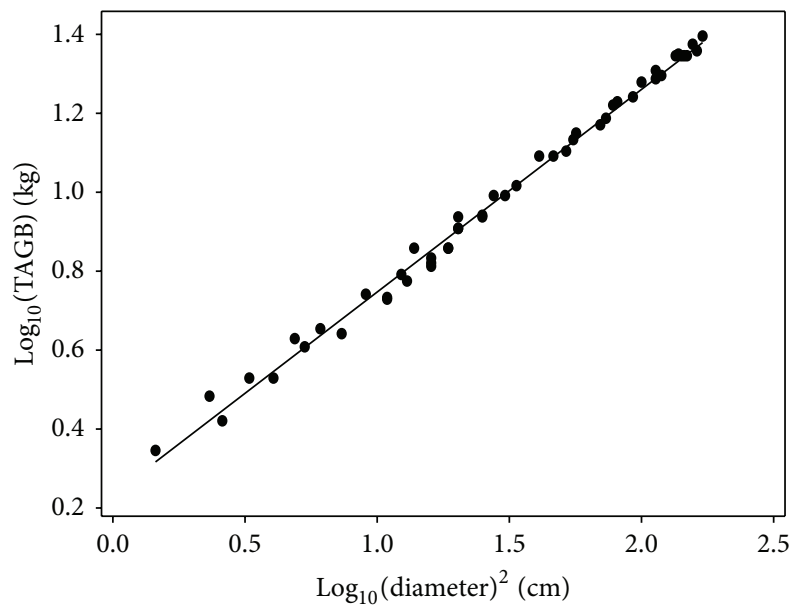

(c)

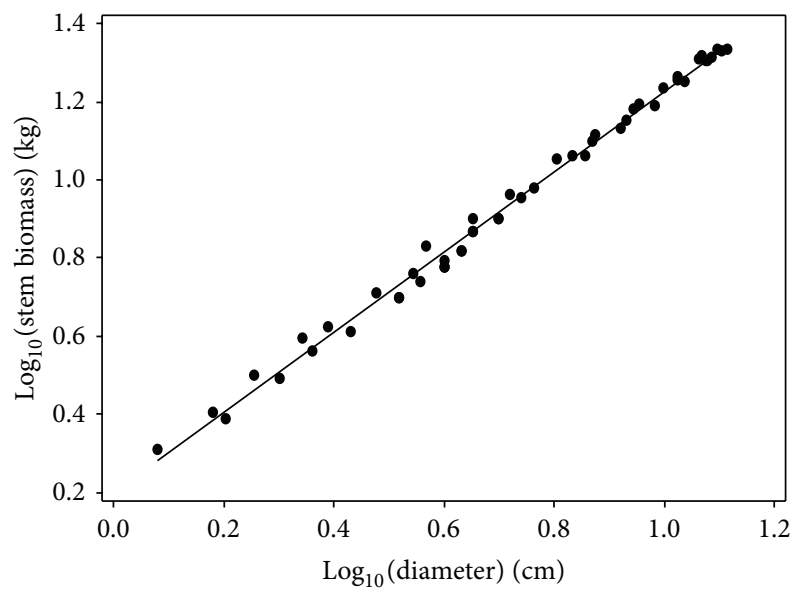

(e)

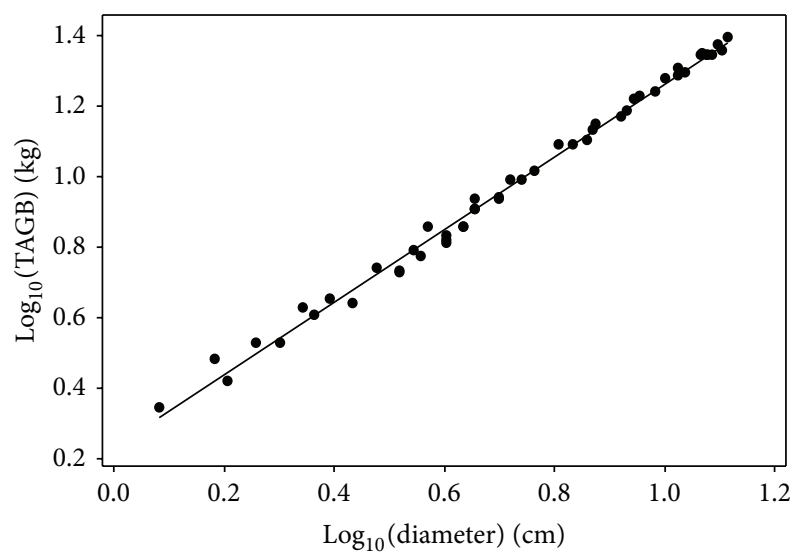

(b)

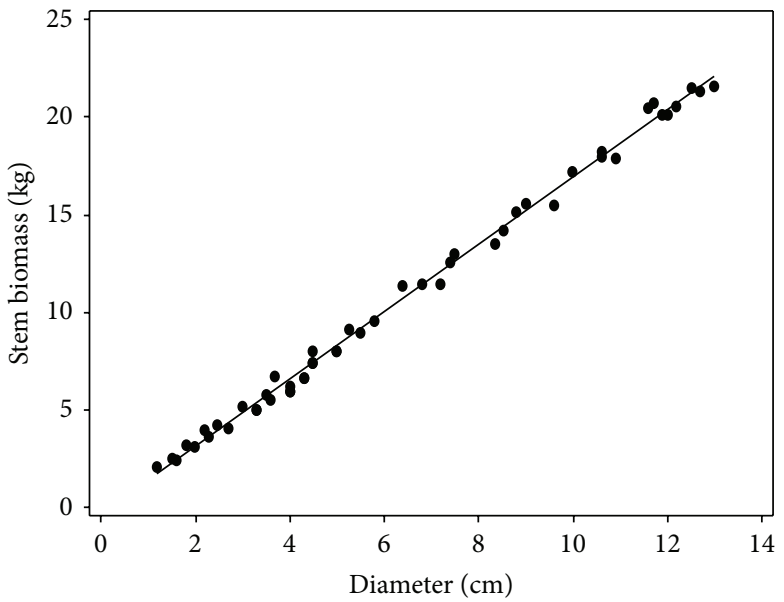

(d)

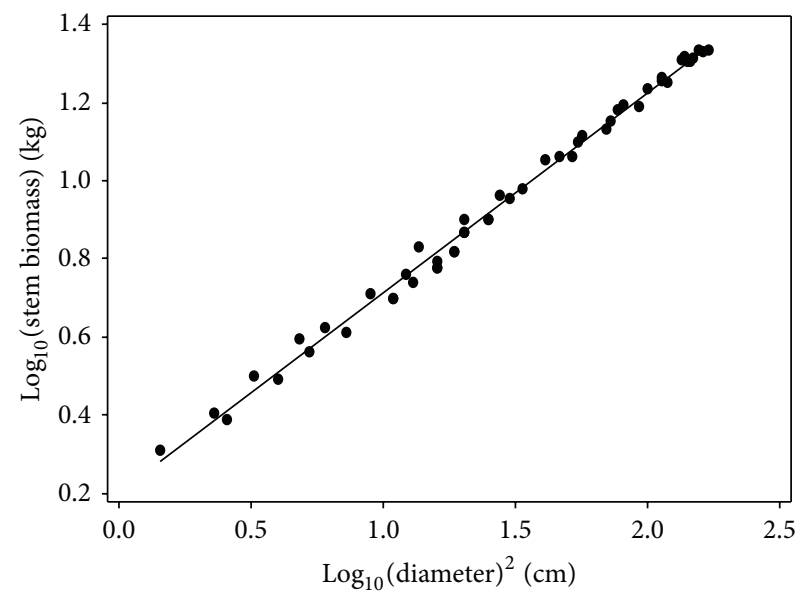

(f)

FIGURE 2: Allometric relationships between liana biomass (total above-ground biomass, TAGB: (a), (b), and (c); stem biomass: (d), (e), and (f)) and diameter in the secondary forest. Relationships based on raw and log-transformed data are shown.

Logarithmic transformation of data resulted in increased homogeneity of variance compared with data on arithmetic scale (Figures 1 and 2). The decline in homogeneity of variance of the log-transformed models is consistent with previous studies $[13,28]$.
On the basis of Furnival's index of fit, the log-transformed allometric equations performed better than the equations fitted to data on original arithmetic scale for both liana stem and total above-ground biomass models. The higher goodness of fit of the log-transformed models provides 
TABLE 8: Correction factor (CF) of logarithmic models for stem and total above-ground biomass of lianas.

\begin{tabular}{|c|c|c|}
\hline \multirow{2}{*}{ Model } & \multicolumn{2}{|c|}{$\mathrm{CF}$} \\
\hline & Stem & Total \\
\hline \multicolumn{3}{|l|}{ Primary } \\
\hline $\log _{10}($ Biomass $)=c+\alpha\left(\log _{10} D\right)$ & 1.0035 & 1.0030 \\
\hline $\log _{10}($ Biomass $)=c+\alpha\left(\log _{10} D^{2}\right)$ & 1.0035 & 1.0030 \\
\hline \multicolumn{3}{|l|}{ Secondary } \\
\hline $\log _{10}($ Biomass $)=c+\alpha\left(\log _{10} D\right)$ & 1.0013 & 1.0014 \\
\hline $\log _{10}($ Biomass $)=c+\alpha\left(\log _{10} D^{2}\right)$ & 1.0013 & 1.0014 \\
\hline
\end{tabular}

TABLE 9: Comparison of mean estimated total above-ground biomass (per species) between model 7 and previous models (see Table 3) with $t$-test in the primary forest. The value in parenthesis represents the mean biomass for the current equation, whereas those outside the parenthesis represent the means of the previous equations.

\begin{tabular}{lcc}
\hline Pair & Mean & $P$ value \\
\hline $\begin{array}{l}\text { This study versus Gehring et al. } \\
\text { (2004) [17] }\end{array}$ & $50.96(126.96)$ & $<0.001$ \\
$\begin{array}{l}\text { This study versus Gerwing and } \\
\text { Farias (2000) [12] }\end{array}$ & $119.80(126.96)$ & 0.502 \\
$\begin{array}{l}\text { This study versus Putz (1983) [18] } \\
\text { This study versus Hozumi et al. }\end{array}$ & $39.27(126.96)$ & $<0.001$ \\
$\begin{array}{l}\text { (1969) [19] } \\
\text { This study versus Beekman }\end{array}$ & $48.18(126.96)$ & $<0.001$ \\
$\begin{array}{l}\text { (1981) [20] } \\
\text { This study versus Schnitzer et al. } \\
\text { (2006) [4] }\end{array}$ & $55.97(126.96)$ & $<0.001$ \\
\hline
\end{tabular}

evidence in support of another study which indicated that log-transformed models show better fit than models of untransformed data [29]. Based on the FI, models 3 and 4 in the primary forest and models 11 and 12 in the secondary forest were the best allometric models for liana stem biomass. In the same way, models 7 and 8 in the primary forest and models 15 and 16 in the secondary forest were the best models for total above-ground liana biomass. Since the log-transformed models that use diameter are simpler than the models that employ [diameter] ${ }^{2}$, models 3 , and 11 are recommended for liana stem biomass estimation in primary and secondary forests, respectively, in line with the Ockham's Razer principle [30]. The principle suggests the selection of simplest models if there are many models that have equal goodness of fit. Likewise, models 7 and 15 are recommended for estimating total above-ground biomass of lianas in primary and secondary forests, respectively. The correction factor values determined for the various logtransformed allometric equations (Table 8) were very low (primary forest: $0.3-0.35 \%$; secondary forest: $0.13-0.14 \%$ ), indicating that downward bias of the models was negligible. A similar finding was reported by Addo-Fordjour and Rahmad [15].

One of the best total above-ground models in the primary forest (model 7) was compared with some previously
TABLE 10: Comparison of mean estimated total above-ground biomass (per species) between model 15 and previous models (see Table 3) with $t$-test in the secondary forest. The value in parenthesis represents the mean biomass for the current equation, whereas those outside the parenthesis represent the means of the previous equations.

\begin{tabular}{lcc}
\hline Pair & Mean & $P$ value \\
\hline $\begin{array}{l}\text { This study versus Gehring et al. } \\
\text { (2004) [17] }\end{array}$ & $130.10(40.97)$ & $<0.001$ \\
$\begin{array}{l}\text { This study versus Gerwing and } \\
\text { Farias (2000) [12] }\end{array}$ & $254.20(40.97)$ & $<0.001$ \\
$\begin{array}{l}\text { This study versus Putz (1983) [18] } \\
\text { This study versus Hozumi et al. }\end{array}$ & $115.96(40.97)$ & $<0.001$ \\
$\begin{array}{l}\text { (1969) [19] } \\
\text { This study versus Beekman }\end{array}$ & $120.10(40.97)$ & $<0.003$ \\
$\begin{array}{l}\text { (1981) [20] } \\
\text { This study versus Schnitzer et al. } \\
\text { (2006) [4] }\end{array}$ & $144.00(40.97)$ & $<0.001$ \\
\hline
\end{tabular}

published models by applying them on a data set taken from the same primary forest. The results indicated that on the whole, most of the previous equations underestimated total above-ground biomass of lianas in this study (Table 9). The mean total above-ground biomass per liana species estimated by five of the previous equations were significantly lower (Table 9; $P<0.05$ ) than that predicted by the current study. Nonetheless, one of the previous allometric equations estimated a mean total above-ground biomass that was similar $(P=0.502)$ to that of the current allometric equation. Another allometric equation selected as one of the best total above-ground model in the secondary forest of this study (model 15) was compared with the previously mentioned equations in the same manner, using a data set collected from the secondary forest. All the previous equations highly over-predicted total above-ground biomass of lianas in the secondary forest (Table 10). The mean total above-ground biomass per species estimated by all the previous equations differed significantly from that estimated by the current model (Table 10; $P<0.05$ ). The equation of Schnitzer et al. [4] which is considered as somewhat general (because it was developed from large data sets from four different countries) also estimated total above-ground biomass that differed considerably from those of the current models in both the primary and secondary forests. Similarly, in a study in Malaysia, a universal equation of Brown [31] highly overestimated total above-ground biomass of trees by as much as $100 \%$ compared with the equation developed in that study [32]. The wide disparities between the estimation powers of the site specific and general allometric equations of plants observed in this study as well as that of Kenzo et al. [32] indicate that general allometric equations may not provide accurate biomass estimation in specific forests. The differences in estimation of total above-ground biomass between the previous and the current models may be due to differences in liana wood density in the various forests from which the equations were developed $[32,33]$. The comparison of the previous equations to the current ones has revealed the 
need for site specific models to be encouraged for accurate determination of liana biomass in tropical forests. However, where site specific allometric equations are not available, care must be taken when choosing allometric equations for forests. As much as possible, equations from the same region or continent should be given preference to equations from different continents [15].

\section{Conclusion}

The current study developed allometric relationships between liana biomass, diameter, [diameter $]^{2}$, and length for the estimation of stem and total above-ground biomass. Forest type had a significant influence on liana allometric models in the current study, resulting in the development of forest-type-specific equations. Models were developed on data fitted to log-transformed and untransformed data. In both forest types, log-transformed data fitted better compared to untransformed data. Comparison of the site specific models in the current study with previously published models indicated that the models of the current study differed from the previous ones.

\section{Conflict of Interests}

The authors wish to state that they do not have any direct financial relation whatsoever with the content of this paper, that might lead to a conflict of interest for any of them. Consequently, they declare no conflict of interests.

\section{Acknowledgments}

This study was supported by TWAS-USM Postgraduate Fellowship and Research University Grant (RU) (1001/PBIOLOGI/815086). The authors are grateful to Mr. Abu Husin from the Forest Research Institute Malaysia and Mr. Ntim Gyakari of the Forestry Commission of Ghana for their assistance in plant identification. The authors finally thank Mr. S. M. Edzham from the School of Biological Sciences, USM, Malaysia, for his immense assistance on the field.

\section{References}

[1] L. Kammesheidt, A. Berhaman, J. Tay, G. Abdullah, and M. Azwal, "Liana abundance, diversity and tree infestation in the Imbak Canyon conservation area, Sabah, Malaysia," Journal of Tropical Forest Science, vol. 21, no. 3, pp. 265-271, 2009.

[2] S. A. Schnitzer and F. Bongers, "The ecology of lianas and their role in forests," Trends in Ecology and Evolution, vol. 17, no. 5, pp. 223-230, 2002.

[3] P. Addo-Fordjour, A. K. Anning, E. A. Atakora, and P. S. Agyei, "Diversity and distribution of climbing plants in a semi-deciduous rain forest, KNUST Botanic Garden, Ghana," International Journal of Botany, vol. 4, no. 2, pp. 186-195, 2008.

[4] S. A. Schnitzer, S. J. DeWalt, and J. Chave, "Censusing and measuring lianas: a quantitative comparison of the common methods," Biotropica, vol. 38, no. 5, pp. 581-591, 2006.
[5] Y. Tang, R. L. Kitching, and M. Cao, "Lianas as structural parasites: a re-evaluation," Chinese Science Bulletin, vol. 57, no. 4, pp. 307-312, 2012.

[6] Z. Q. Cai, L. Poorter, K. F. Cao, and F. Bongers, "Seedling growth strategies in bauhinia species: comparing lianas and trees," Annals of Botany, vol. 100, no. 4, pp. 831-838, 2007.

[7] B. Kusumoto, T. Enoki, and Y. Kubota, "Determinant factors influencing the spatial distributions of subtropical lianas are correlated with components of functional trait spectra," Ecological Research, vol. 28, no. 1, pp. 9-19, 2013.

[8] J. Chave, D. Coomes, S. Jansen, S. L. Lewis, N. G. Swenson, and A. E. Zanne, "Towards a worldwide wood economics spectrum," Ecology Letters, vol. 12, no. 4, pp. 351-366, 2009.

[9] D. Tilman, P. B. Reich, J. Knops, D. Wedin, T. Mielke, and C. Lehman, "Diversity and productivity in a long-term grassland experiment," Science, vol. 294, no. 5543, pp. 843-845, 2001.

[10] Q. M. Ketterings, R. Coe, M. van Noordwijk, Y. Ambagau', and C. A. Palm, "Reducing uncertainty in the use of allometric biomass equations for predicting above-ground tree biomass in mixed secondary forests," Forest Ecology and Management, vol. 146, no. 1-3, pp. 199-209, 2001.

[11] D. B. MacKay, P. M. Wehi, and B. D. Clarkson, "Evaluating restoration success in urban forest plantings in Hamilton, New Zealand," Urban Habitats, vol. 6, no. 1, 2011.

[12] J. J. Gerwing and D. L. Farias, "Integrating liana abundance and forest stature into an estimate of total aboveground biomass for an eastern Amazonian forest," Journal of Tropical Ecology, vol. 16, no. 3, pp. 327-335, 2000.

[13] J. R. Moore, "Allometric equations to predict the total aboveground biomass of radiata pine trees," Annals of Forest Science, vol. 67 , no. 8 , article $806,2010$.

[14] M. Segura and M. Kanninen, "Allometric models for tree volume and total aboveground biomass in a tropical humid forest in Costa Rica," Biotropica, vol. 37, no. 1, pp. 2-8, 2005.

[15] P. Addo-Fordjour and Z. B. Rahmad, "Development of allometric equations for estimating above-ground liana biomass in tropical primary and secondary forests, Malaysia," International Journal of Ecology, vol. 2013, Article ID 658140, 8 pages, 2013.

[16] M. A. Cairns, S. Brown, E. H. Helmer, and G. A. Baumgardner, "Root biomass allocation in the world's upland forests," Oecologia, vol. 111, no. 1, pp. 1-11, 1997.

[17] C. Gehring, S. Park, and M. Denich, "Liana allometric biomass equations for Amazonian primary and secondary forest," Forest Ecology and Management, vol. 195, no. 1-2, pp. 69-83, 2004.

[18] F. E. Putz, "Liana biomass and leaf area of a "tierra firme" forest in the Rio Negro Basin, Venezuela," Biotropica, vol. 15, no. 3, pp. 185-189, 1983.

[19] K. Hozumi, K. Yoda, S. Kokawa, and T. Kira, "Production ecology of tropical rain forests in South-Western Cambodia. I. Plant biomass," Oecologia, vol. 145, pp. 87-99, 1969.

[20] F. Beekman, Structural and Dynamic Aspects of the Occurrence and Development of Lianes in the Tropical Rain Forest, Department of Forestry, Agricultural University, Wageningen, The Netherlands, 1981.

[21] P. Addo-Fordjour, Z. B. Rahmad, J. Amui, C. Pinto, and M. Dwomoh, "Patterns of liana community diversity and structure in a tropical rainforest reserve, Ghana: effects of human disturbance," African Journal of Ecology, vol. 51, no. 2, pp. 217-227, 2013.

[22] P. Addo-Fordjour, P. El Duah, and D. K. K. Agbesi, "Factors influencing liana species richness and structure following 
anthropogenic disturbance in a tropical forest, Ghana," ISRN Forestry, vol. 2013, Article ID 920370, 11 pages, 2013.

[23] B. R. Parresol, "Assessing tree and stand biomass: a review with examples and critical comparisons," Forest Science, vol. 45, no. 4, pp. 573-593, 1999.

[24] R. J. Hyndman and A. B. Koehler, "Another look at measures of forecast accuracy," International Journal of Forecasting, vol. 22, no. 4, pp. 679-688, 2006.

[25] G. M. Furnival, "An index for comparing equations used inconstructing volume tables," Forest Science, vol. 7, pp. 337-341, 1961.

[26] G. L. Baskerville, "Use of logarithmic regression in the estimation of plant biomass," Canadian Journal of Forest Research, vol. 2, no. 1, pp. 49-53, 1972.

[27] D. G. Sprugel, "Correcting for bias in log-transformed allometric equations," Ecology, vol. 64, no. 1, pp. 209-210, 1983.

[28] H. P. Piepho, "Data transformation in statistical analysis of field trials with changing treatment variance," Agronomy Journal, vol. 101, no. 4, pp. 865-869, 2009.

[29] C. Wang, "Biomass allometric equations for 10 co-occurring tree species in Chinese temperate forests," Forest Ecology and Management, vol. 222, no. 1-3, pp. 9-16, 2006.

[30] D. J. C. Mackay, Information Theory, Inference and Learning Algorithms, Cambridge University Press, Cambridge, UK, 2003.

[31] S. Brown, "Estimating biomass and biomass change in tropical forests. a primer," Forestry Paper 134, Food and Agriculture Organization of the United Nations, Rome, Italy, 1997.

[32] T. Kenzo, T. Ichie, D. Hattori et al., "Development of allometric relationships for accurate estimation of above- and belowground biomass in tropical secondary forests in Sarawak, Malaysia," Journal of Tropical Ecology, vol. 25, no. 4, pp. 371-386, 2009.

[33] T. Kenzo, R. Furutani, D. Hattori et al., "Allometric equations for accurate estimation of above-ground biomass in loggedover tropical rainforests in Sarawak, Malaysia," Journal of Forest Research, vol. 14, no. 6, pp. 365-372, 2009. 

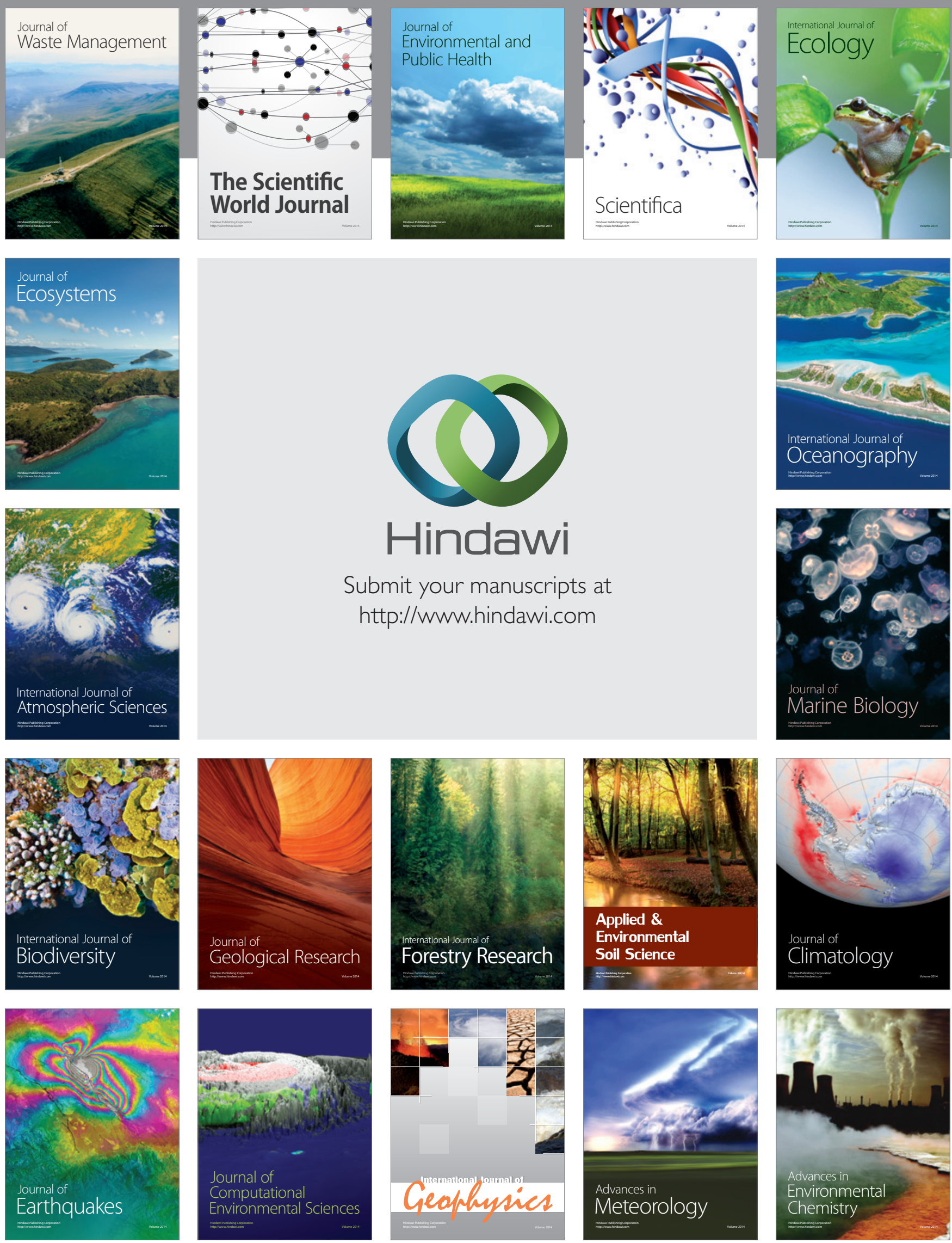